\title{
Using Large Number Estimation Problems in Primary Education Classrooms to Introduce Mathematical Modelling
}

\author{
Lluís Albarracín ${ }^{\mathrm{a}, \mathrm{b}}$ and Núria Gorgorióa \\ Corresponding author: 1luis.albarracin@uab.cat \\ aDepartament de Didàctica de la Matemàtica i les Ciències Experimentals, Universitat Autònoma de Barcelona, \\ Bellaterra, Barcelona, 08193, Spain \\ bLluís Albarracín is Serrra Húnter Fellow in Universitat Autònoma de Barcelona
}

Keywords: Problem solving, estimation, modelling, Primary Education

International Journal of Innovation in Science and Mathematics Education, 27(2), 45-57, 2019

\begin{abstract}
In this work we study the development of mathematical models by students in the upper cycle of Primary Education (10 and 11 years old) to Large Number Estimation Problems. After a qualitative analysis of their output, we found that, when students worked on problems in teams, they used strategies including the development of mathematical models such as the grid distribution, the iteration of a reference point model, or population density. The results obtained allow us to argue that the use of Large Number Estimation Problems is a suitable activity for introducing mathematical modelling processes in Primary School classrooms. In previous studies (Albarracín \& Gorgorió, 2013; 2014; 2018; Gallart, Ferrando, García-Raffi, Albarracín, \& Gorgorió, 2017), we have analysed the solving strategies proposed by Secondary School students (ages 12-16) to solve Large Number Estimation Problems (LNEP). These studies show that students solve these problems by proposing their own strategies, breaking them up into smaller problems and solving them separately (Albarracín \& Gorgorió, 2014). Thus, LNEP are a subgroup of so-called Fermi Problems that we have verified to be a useful tool for introducing the modelling process in Secondary School classrooms (Albarracín \& Gorgorió, 2013).
\end{abstract}

\section{Introduction}

Since the International Commission on Mathematical Instruction (ICMI) study 14 on Applications and Modelling in Mathematics Education (Blum, 2002), a movement has emerged in Mathematical Education with the main idea of creating classroom activities that manifest the close relationship between Mathematics and the world around us. The literature produced in recent years has shown a rise in educational proposals that incorporate mathematical modelling at different educational levels (Vorhölter, Kaiser, \& Borromeo-Ferri, 2014). In general, efforts have been directed at studying the possibilities of students in Secondary Education and at university level, but studies including Primary School students are scarce. In this article, we present an investigation based on different classroom experiences with students from the upper cycle of Primary Education, in which we use a series of LNEP. In the analysis of these students' output, we detect the creation of mathematical models arising from the students' teamwork and characterise them.

In previous studies we have noted that solving LNEP enables Secondary School students to establish connections between their own mathematical knowledge and their environment as when they develop the concept of population density from the knowledge of the amount of surface required by an object when counting trees in a given area of forest (Albarracín \& 
Gorgorió, 2018). We now wonder about the possibilities of introducing such tasks involving mathematical modelling to younger students, as previously explored by Peter-Koop (2004) in a case study. Students facing problems that connect elements of their daily life with mathematics allows them to build on their real-life knowledge to generate their own mathematical knowledge (Ärlebäck, 2009).On the other hand, it is well known that classroom problems with real-life contexts are not a substitute for decision-making in the real world, but their use in classrooms promotes attitudes that may be used in daily life (Jurdak, 2006). For this reason, the problems proposed in this work are based on the estimation of large numbers and set in a context that is close to the students, such as the school itself. When students face problems where the numbers are greater than those they are used to dealing with on a day-today basis, they are forced to deal with them from a mathematical analysis perspective which is what confers their potential to Fermi problems.

\section{Mathematical modelling}

Problem resolution is a key area that has seen great advancement in recent decades, to the point that it now plays a fundamental role in the field of Mathematics Education (Lester, 1994; Schoenfeld, 2007). Part of the progress made in the field of problem resolution knowledge has been collected in studies on mathematical modelling processes. In this work, we advocate that contextualised problem resolution activities can be interpreted as mathematical modelling activities according to the type of mathematical constructs created by the students to solve them. Thus, we consider an activity to be a modelling activity when mathematical models are used or constructed by students. Here we consider the definition of mathematical model proposed by Lesh and Harel (2003):

Models are conceptual systems that generally tend to be expressed using a variety of interacting representational media, which may involve written symbols, spoken language, computer-based graphics, paper-based diagrams or graphs, or experience-based metaphors. Their purposes are to construct, describe or explain other system(s).

Models include both: (a) a conceptual system for describing or explaining the relevant mathematical objects, relations, actions, patterns, and regularities that are attributed to the problem-solving situation; and (b) accompanying procedures for generating useful constructions, manipulations, or predictions for achieving clearly recognised goals. (p. 159)

From this definition we understand that a mathematical model is a way of representing a reality where elements of a different nature intervene, both conceptual and procedural. Some of these elements are mathematical, but the models constructed may also contain non-formal aspects that enable an intuitive description of the reality studied. Specifically, we understand that Primary School students do not have yet the mathematical language tools that are normally used to represent models - as in, for instance, algebra or graphical representations - though they are able to use natural written language and calculations to express their ideas. In this sense, in previous work we have used an analysis tool to characterise mathematical models in the students' output based on the procedures and concepts shown (Gallart, Ferrando, GarcíaRaffi, Albarracín, \& Gorgorió, 2017). 
The way students create mathematical models to solve problems is currently under study, with differing viewpoints existing on this matter (Borromeo Ferri, 2006). In general, it is accepted that modelling processes are cyclic in nature. During the resolution process, the students try to solve problems by going through different stages and then going back to reassess the situation studied. Therefore, the process is repeated in different cycles in which the students improve the models and solutions found for the problem they are working on, adapting to the requirements of the problem statement (Blum \& Borromeo Ferri, 2009).

\section{Estimation and Fermi problems}

In many everyday-life situations, the resources or information needed to give a precise and concrete answer to a given question are not available to us. However, in many of these situations, it is not actually necessary to reach highly precise answers to solve the issue at hand. In these cases, an estimation of the relevant quantities involved in the situation we find ourselves in can be enough or may even be the quickest and most effective option to solve the problem. According to Bright (1976), estimation is a process by which a value is reached without the aid of tools and is therefore a mental process with visual or manipulative aspects. Some of the daily life situations where an estimate is the right type of response are as follow: show long would I take to get to the metro station? Would a kilogram of potatoes be enough to feed eight people with this recipe? Or, would all of these clothes fit in the small suitcase or should I use a larger one? More recently, Van de Walle, Karp and Bay-Williams (2010) stated that estimation refers to obtaining a value that is a suitable approximation for an exact number in a given context, supported by some type of reasoning. In this case, estimation is a suitable approximation that may encompass different processes sustained by mathematical reasoning.

In existing literature, a distinction between three essentially different types of estimation is evident: so-called numerosity, measurement estimation and computational estimation (Hogan \& Brezinski, 2003). On the other hand, another type of activity with mathematics as a fundamental aspect, and that is also called estimation, is the calculation of values obtained in predictive activities, involving the approximation of a reality based on the use of models that represent a situation. This type of activity is common in scientific and technical tasks, or in social studies of the highest level, such as in the estimation of the GDP increase of a country or the estimation of the scaled distances of the solar system. However, even though estimation based on modelling work is used in scientific works, it has not been considered in the field of Mathematics Education.

A good example of the type of situation in which a mathematical model is the basis for estimating a given quantity - and that can be applied in Primary Education classrooms - are so-called Fermi problems, originally proposed by Enrico Fermi (1901-1954), Nobel prizewinning physicist, to show the power of deductive thinking and to prepare this student for experimental laboratory work with the goal to save time and be more effective (Efthimiou \& Llewellyn, 2007). For the purposes of this paper we define Fermi problems as "estimation problems used with the pedagogical purpose of clearly identifying starting conditions or assumptions and making educated guesses about various quantities or variables which arise within a problem with the added requirement that the end computation be feasible or computable by hand" (Sriraman \& Knott, 2009, p. 220).

The most prominent characteristic that defines Fermi problems is the way in which their solutions are achieved. Enrico Fermi posed problems which at first seemed impossible to solve, but that could be tackled by making assumptions based on common knowledge and following 
simple chains of reasoning. The procedure proposed by Fermi to his students was to decompose the original problem into simpler sub-problems to reach a solution of the original question by means of reasonable estimates or educated guesses (Carlson, 1997). Robinson (2008) relates this specific resolution process to the creation of physical models, in which the students must examine the physical principles in operation, determine other constraints such as boundary conditions, decide how simple the model could be while still maintaining some realism, and only then apply a rough estimation to the problem. On the other hand, Ärlebäck (2011) states that working with Fermi problems can be useful to introduce modelling in mathematical classrooms since they are accessible to students of different educational levels. In addition, Fermi problems do not require any particular type of previous mathematical knowledge, and they oblige the students to define the mathematical structure of the information given. Solving a Fermi problem requires a creative process, allowing a classroom proposal away from teaching rules and algorithms and favouring the academic achievement of students in solving problems (Tok, Bahtiyar, \& Karalök, 2015). Another argument for the introduction of Fermi problems in classrooms is the possibility of using them as a bridge between mathematics and other school subjects, approaching the students to different interdisciplinary tasks (Sriraman \& Knott, 2009). They also allow for incorporating interesting social issues, such as estimating the amount of drinking water consumed, the consumption of petrol or other fuels, the amounts of food wasted, and other types of ecological problems.

Fermi problems have mainly been used as an educational tool for university studies in the Physical Sciences. However, the use of Fermi problems has also been proposed in other scientific fields, with the aim of connecting mathematical knowledge with issues in phenomena interpretation of other scientific branches. For instance, as described by White (2004) for the study of molecules in the field of Biochemistry, or quantity estimation in the context of economic problems (Anderson \& Sherman, 2010). As mentioned, investigations in recent years have gone deeper into the use of Fermi problems in mathematics classrooms (Ärlebäck, 2009; Albarracín \& Gorgorió, 2014). Educational proposals based on this type of problems can be found in Albarracín and Gorgorió (2015).

However, Fermi problems have not been used extensively in Primary School mathematics classrooms, despite existing evidence suggesting that their adaptability to different educational levels would encourage rich classroom dynamics. The only academic reference to the study of the use of Fermi problems for the introduction of modelling at Primary Educational levels is Peter-Koop's (2004) work, who promotes their use and connects them to mathematical modelling activities and to the modelling cycle. Peter-Koop's detailed analysis of the students' resolution process demonstrates that students generate new mental structures to solve the problem. These structures may be found in the formal mathematic domain, but in this work the type of mathematical models developed by the students are not analysed in detail.

\section{Aim of this study}

Based on the aforementioned background and previous work, we decided to use Large Number Estimation Problems (LNEP) as Fermi problems in the upper cycle of Primary Education (ages 10-11) to characterise the strategies used by these students and identify the mathematical models developed during their teamwork. 


\section{Methods}

In the following sections, we explain the methodological aspects of this study, detailing the participant population, the type of activities and problems used, and the format of the data collected.

\section{Participants}

The data of the present study were collected from the output of students in the $5^{\text {th }}$ and $6^{\text {th }}$ grades of Primary Education (ages 10 to 11) from two different schools, who had not previously worked on this type of problems. An informed consent was collected from the parents and legal tutors of all participating students who were informed of the activities and that all data collected would be anonymous and used exclusively in the research. In the classroom, the students worked in teams of 3 to 4 . Table 1 shows the total number of students for each year that participated in the activity and the number of working teams they were divided into.

Table 1: Number of students in each school and number of working teams

\begin{tabular}{ccc}
\hline & $\begin{array}{c}\text { Number of } \\
\text { students }\end{array}$ & $\begin{array}{c}\text { Working } \\
\text { teams }\end{array}$ \\
\hline Year 5 & 45 & 12 \\
Year 6 & 48 & 13 \\
Total & 93 & 25 \\
\hline
\end{tabular}

\section{Problems}

For this study, we used several LNEP, which are a specific type of Fermi Problems (Albarracín \& Gorgorió, 2014). One of the key aspects in the use of large numbers is that it hinders exhaustive counting or direct measurements, thus forcing the students to develop their own alternative strategies to carry out and justify their estimations. In order to design these activities, we used problems set in the students' educational centre, considering that familiarity with the context should promote more interesting and approachable problems while also allowing for taking measurements in an accessible location as needed.

The problems used are divided into two different types as follows:

Type A: Estimation of the number of people that can be arranged across a given surface area.

Type B: Estimation of the quantity of objects that can be arranged across a given surface area or fit into a certain volume.

Contextualised statements for the problems were provided for each of the activities. In type A problems, the students were asked the amount of people that would fit on a certain surface area and the context is given by an image showing the location where the people should be placed. For instance, Figure 1 shows one of the problem statements proposed for type A problems. 


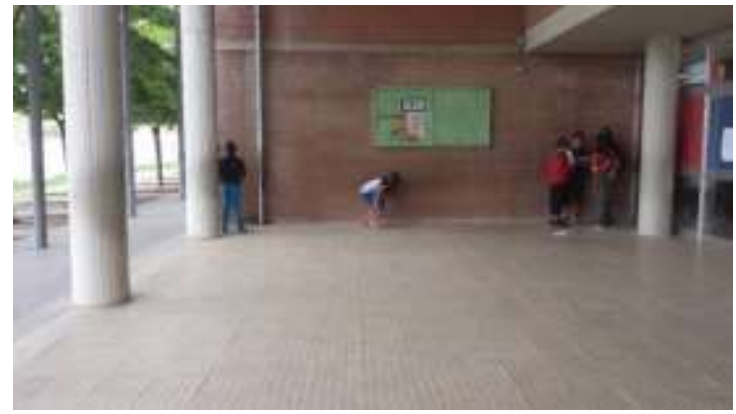

Figure 1. Image for the problem: How many people fit under this porch?

The statements for type B problems follow the same structure as type A problems, but the nature of the objects involved in the problems is varied. Figure 2 shows the statement provided to the students for a type $\mathrm{B}$ problem which requires estimating the quantity of books that would fit in the school library.

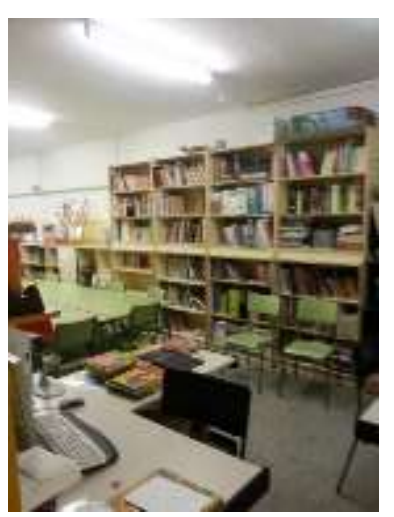

Figure 2. Image for the problem: How many books are there on these bookshelves?

The following is a complete list of type B problems used in a data collection session:

B1: How many sheets of paper are there on a stack such as the one on the desk?

B2: How many books are there on the shelves in the library?

B3: How many bricks are there on this wall?

B4: How many footballs could fit in the central circle of the sports field?

B5: How many squares make up the net that stops footballs from escaping the field?

\section{Design of the classroom experience and data collection}

Each of the experiences accomplished are based on the work on a sequence of 4 LNEP, with localised problem statements to each classroom or school. In the classroom the students worked in teams of 3 or 4 for two hour-long sessions. In the first session the problems were set and the students were asked to design an action plan to solve them, and were given time to tackle the resolution process and to conduct the appropriate measurements. In the second session the students wrote a team report of the processes followed and the results obtained. The exercise ends with the students sharing their results. During these sessions the role of the teacher is to guide and answer the students' questions about problem statements, encouraging the workflow in the classroom without providing any help to problem resolution.

Thus the data analysed is the written production of the students for the resolutions of each of the problems set. To enable the adequate interpretation of the students' written output, we used the field notes of the researchers present in the classroom. Since each group worked on one type A problem and three type B problems, we obtained 25 resolutions for type A and 75 for 
type B. Table 2 shows the number of productions collected for each specific type B problem proposed per year.

Table 2: Number of resolutions collected for each type B problem

\begin{tabular}{cccccc}
\hline & $\begin{array}{c}\text { B1: Stacked } \\
\text { sheets of } \\
\text { paper }\end{array}$ & $\begin{array}{c}\text { B2: Library } \\
\text { books }\end{array}$ & $\begin{array}{c}\text { B3: bricks on } \\
\text { the wall }\end{array}$ & $\begin{array}{c}\text { B4: balls in } \\
\text { pitch }\end{array}$ & $\begin{array}{c}\text { B5: squares on } \\
\text { the net }\end{array}$ \\
\hline Year 5 & 12 & 6 & 6 & 6 & 6 \\
Year 6 & 6 & 6 & 13 & 7 & 7 \\
Total & 18 & 12 & 19 & 13 & 13 \\
\hline
\end{tabular}

\section{Analysis}

To analyse the students' problem resolutions, we considered the precedents of this investigation in terms of the different resolution strategies and models detected in the resolution of LNEP (Albarracín \& Gorgorió, 2013; 2014) that led to the development of the analysis tool presented in Gallart, Ferrando, García-Raffi, Albarracín and Gorgorió (2017), based on Lesh and Harel's (2003) definition of mathematical model. Each resolution collected in each of the teams' work shows a series of actions and previous decisions leading to the use of specific mathematical procedures and concepts. What we identify clearly in the students' work is the procedures developed, since it is hard for students of their age to explicitly describe the mathematical concepts used. These procedures and concepts can be counts, direct or indirect measurements based on the use of formulas, or estimations supported by a certain way of interpreting the studied phenomenon.

Since our work stems from our previous experience analysing the outputs of Secondary School students, we set out with a preliminary set of identified strategies, some of which are based on the creation of a mathematical model. These strategies to solve LNEP are explained in detail in Albarracín and Gorgorió (2014) and are listed as follows:

- Exhaustive count: the students' strategy is to count all the elements in the group of objects, one by one.

- External source: the students delegate the responsibility of giving an answer to the problem to a third party that should possess the information required.

- Reduction and use of proportion: the students consider the initial problem and try to solve an equivalent problem with smaller values in order to give an answer to the initial problem using a proportion factor between the two situations.

- Concentration measures: the resolution is based on determining the amount of people or objects arranged across a portion of a given surface area that they have determined themselves, as in the case of population density.

- Reference point: the students determine the total surface area of the location where the people or objects to be estimated should be placed and they divide it by the surface area occupied by one single object, which acts as a unit called reference point (Joram, Gabriele, Bertheau, Gelman, \& Subrahmanyam, 2005).

- Grid distribution: the students use a mental image of the distribution of people or objects on a grid, they estimate their number for each dimension (height and width in the case of surfaces), and they use the product rule to establish a result. 
Here we show the type of data and the analysis process developed to identify the mathematical models elaborated by the students. Specifically, Figure 3 shows an extract of the resolution report of a team of four $6^{\text {th }}$ grade Primary School students. The text shown is the following:

"We placed a girl along the lines of the pitch, and we got 50 of her along and 25 across. Then, if we multiply 50x25 we get 1250, and if we multiply that again by 2 we get 2500 people".

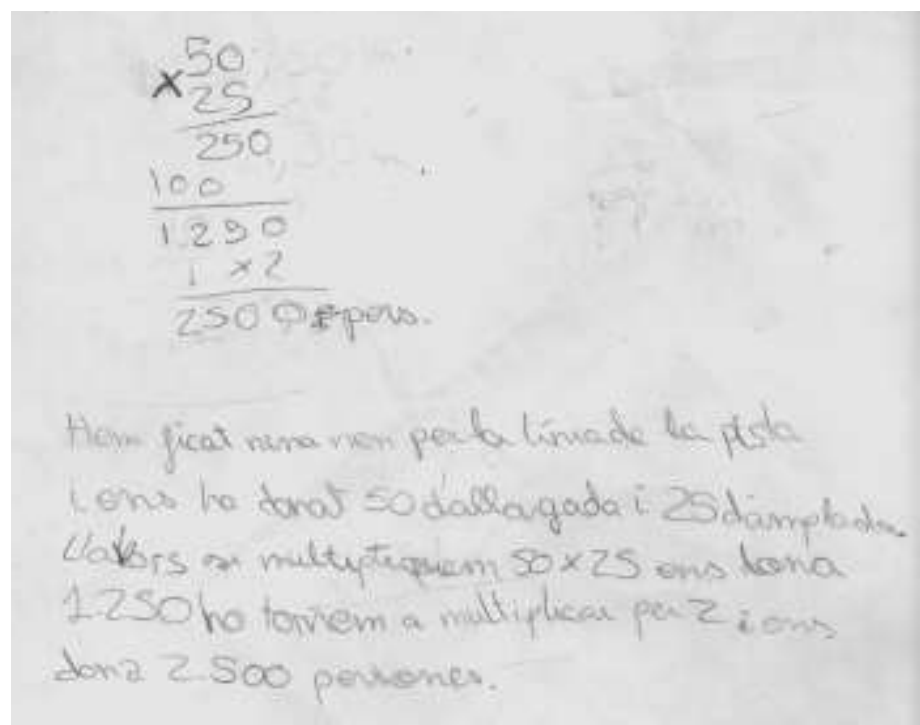

Figure 3: Output of a team that solved a problem using the grid distribution method.

These students tried to estimate the number of people that can fit on the pitch of their school playground in the resolution of one of the type A problems proposed. Figure 4 shows the students counting the number of people that can fit along the straight lines that define the rectangle shaping the pitch by counting steps, both along and across the playground.

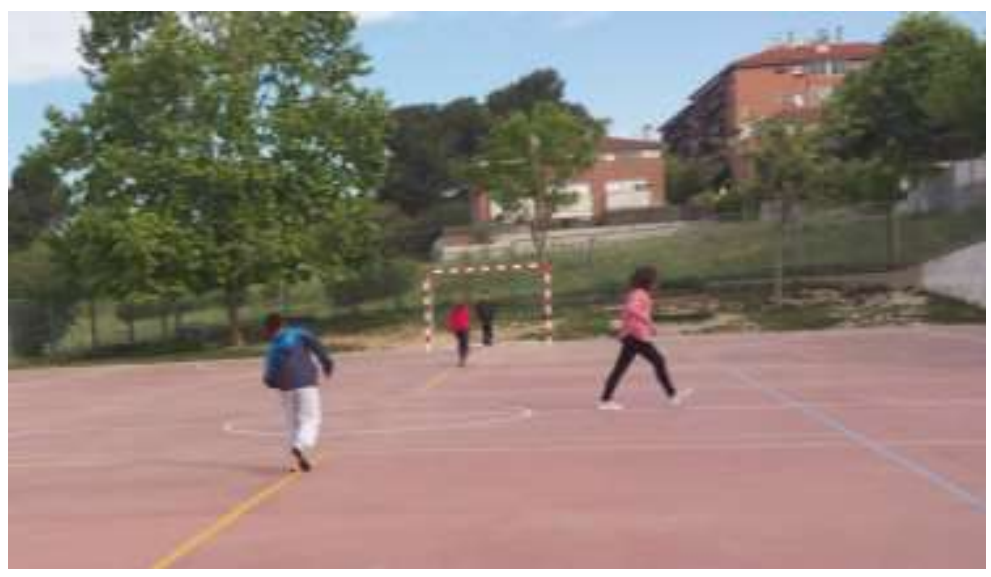

Figure 4: Example of the students' work; each step equals a person.

These students' work on the problem is detailed in the report they handed in and where an extract of Figure 4 is shown. In their report the students explain the calculations made and give reasons for the process they developed. It specifically shows the partial results for the indirect measurements of the pitch (50 people along by 25 people across) and the calculations made 
based on these values - firstly, a multiplication of the two values and secondly, as their data refers to half of the pitch, they multiply this result by 2 .

These calculations follow the specific actions developed in the playground, such as measuring the length and width of the rectangle with their steps, in order to emulate the space required by a single person. Thus, we can identify measurement procedures that reflect a specific view of the distribution of people in the playground based on a grid distribution. In other cases, the students tried to precisely measure the area of the premises where the people should be located, to then experience how much surface area a person needs when placed next to another and establishing a unit that acts as a reference point obtained from their own measurements.

\section{Results}

In this section we detail the strategies used by the students and the models detected in each type of problem.

\section{Type A problems}

Table 3 collects the strategies detected in the resolution of type A problems, in which the students have to estimate the amount of people that can fit into a given space:

Table 3: Strategies detected for type A problems

\begin{tabular}{llll}
\hline Strategy & $\begin{array}{l}\text { Number of } \\
\text { Resolutions Year 5 }\end{array}$ & $\begin{array}{l}\text { Number of } \\
\text { Resolutions Year 6 }\end{array}$ & Total \\
\hline Population density & 0 & 1 & 1 \\
Reference point & 3 & 4 & 7 \\
Grid & 8 & 8 & 16 \\
Total & 12 & 13 & 25 \\
\hline
\end{tabular}

According to the results obtained, we can state that all student teams based their strategies on development of mathematical models that simplify and explain the situation to be studied. In Albarracín and Gorgorió (2014) we observed that Secondary School students found it difficult to come up with suitable resolution proposals when working individually. In this work we can see that the potential of teamwork for tackling modelling tasks allows all teams to propose and develop methods to estimate the required amount of people in large spaces.

If we pay attention to the type of strategies used, we will see that for these students the distribution of people on a grid is the predominant model that allows describing the situation at hand and that offers a simple method to work in the field. In previous studies (Albarracín \& Gorgorió, 2014), we noted that the incidence of this strategy is much smaller in Secondary School students (ages 12 to 16), and we therefore understand that Primary School students do not yet have the knowledge to carry out other types of approximations to the problem.

It is worth noting that not all the students applied the proposed methods in the same way and that some of the teams introduced nuances in their resolution that deserve some attention. Two of the teams used the floor tiles of the space where the problem was set, determining the number of tiles that a person takes up and counting the tiles based on the grid distribution. Other teams established the space occupied by a person based on the length of a step, thus obtaining a fast and effective way of counting the number of people that fit along each dimension of the space given. One of the teams sped up the process by estimating the number of people that fit on only 
half of the pitch, multiplying their result by two. These variations are nuances in the model that add complexity to each of the teams' resolutions and show that different models can arise in the same class. This accordingly adds value to any potential discussions. Moreover, variations of the different models can also arise, and the students can enrich the models developed with the contributions of their classmates.

\section{Type B problems}

Table 4 shows the strategies detected in the resolution of type B problems, in which the students have to estimate the quantity of objects (sheets of paper, footballs, books...) that fit in a given space:

Table 4: Strategies detected for type B problems

\begin{tabular}{|c|c|c|c|c|c|c|c|c|c|c|c|}
\hline & $\begin{array}{l}\text { B1 } \\
\text { Year } \\
5\end{array}$ & $\begin{array}{l}\text { B1 } \\
\text { Year } \\
6\end{array}$ & $\begin{array}{l}\text { B2 } \\
\text { Year } \\
5\end{array}$ & $\begin{array}{l}\text { B2 } \\
\text { Year } \\
6\end{array}$ & $\begin{array}{l}\text { B3 } \\
\text { Year } \\
5\end{array}$ & $\begin{array}{l}\text { B3 } \\
\text { Year } \\
6\end{array}$ & $\begin{array}{l}\text { B4 } \\
\text { Year } \\
5\end{array}$ & $\begin{array}{l}\text { B4 } \\
\text { Year } \\
6\end{array}$ & $\begin{array}{l}\text { B5 } \\
\text { Year } \\
5\end{array}$ & $\begin{array}{l}\text { B5 } \\
\text { Year } \\
6\end{array}$ & Total \\
\hline $\begin{array}{l}\text { External } \\
\text { source }\end{array}$ & 1 & 0 & 0 & 0 & 1 & 0 & 0 & 0 & 0 & 0 & 2 \\
\hline $\begin{array}{l}\text { Reduction } \\
\text { to a smaller } \\
\text { problem }\end{array}$ & 5 & 1 & 4 & 3 & 1 & 3 & 3 & 2 & 0 & 2 & 24 \\
\hline Density & 2 & 1 & 0 & 0 & 0 & 0 & 0 & 0 & 0 & 0 & 3 \\
\hline $\begin{array}{l}\text { Reference } \\
\text { point }\end{array}$ & 4 & 4 & 0 & 0 & 0 & 3 & 3 & 5 & 0 & 0 & 19 \\
\hline Grid & 0 & 0 & 2 & 3 & 4 & 7 & 0 & 0 & 6 & 5 & 27 \\
\hline Total & 12 & 6 & 6 & 6 & 6 & 13 & 6 & 7 & 6 & 7 & 75 \\
\hline
\end{tabular}

This type of problem entails more varied formulations than the type A problems proposed, since the nature of the objects to be counted is different. This fact justifies observing a greater variety of strategies used by the students. In this case, the product rule is still the preferred strategy for those problems where the students manage to apply it. However, we observe that the reduction to a smaller problem by proportionality is also a widely used strategy.

It is evident in Table 4 that we did not identify the grid model in two of the problems (B1 and B4), while it is the predominant model in problems B3 and B5 - due to the disposition of the objects to be counted in the latter two problems. In the case of problem B1, it is hard to imagine a resolution proposal based on the grid rule due to the way books are usually arranged on a bookshelf, such as the one in the problem. In such cases the students find alternative strategies. In problem B4 we understand that the difficulty in the use of this model lies in the fact that the space where the balls are located is a circumference. It could be expected for a team to approximate the shape of the circumference by using rectangles, but we have not observed that. In this case, the presence of a circumference generates confusion between the concepts of area and perimeter for the students that opt to use a reference point as base unit. We observed that one of the teams initially tried to solve the problem by aligning some footballs along the perimeter of the circumference, reflecting their confusion between the concept of area and that of perimeter. However, this team finally resolves to also using the reference point model.

It is worth noting that in all type B problems, we found the strategy of reducing the problem by proportionality for each and every one of them. Thus, the students get around the difficulty of solving LNEP by using a very powerful conceptual tool, such as proportion. Students reduce the initial problem in very different ways, generally considering a portion of the total space, 
but devising an approximation to the problem according to the object to be counted and to how it fits into the space. For instance, in the case of problem B2, we find that 9 of the teams tried to solve the problem of estimating the number of books on the library shelves by reducing the situation to a smaller and more manageable problem. In most cases, they chose a small sample of shelves, between 2 and 4, and they counted the number of books they contained. Based on these data, they applied a proportionality factor between the part of the library they counted and the total. We found that the students did not calculate the average number of books on each shelf, and we can thus interpret that this activity could easily be connected to statistical concepts. However, one of the teams considered that the question in problem B2 made no sense, since the problem was already solved in the library catalogue, and they simply answered that the head of the library already had the solution.

In the case of problem B1, in which the number of paper sheets that make up a stack should be estimated, we find that the students reduced the problem in two different ways, corresponding to two different ways of understanding it. One option is to count the number of sheets needed to reach a certain height (e.g. $2 \mathrm{~cm}$ ), and the other is to measure the height of a certain quantity of sheets. Those that used this type of approximation do not calculate the thickness of a single paper sheet, which is the unit of measure that is finally used by those who applied the reference point model. On the other hand, 3 of the teams focussed on finding the number of sheets per each $\mathrm{cm}$ of the pile and work with this value. Again, we can clearly identify that these students are searching for this amount from the beginning, even though they decide to count the number of sheets from a pile with a different height. Thus, we observe that the three models - reference point, reduction to a smaller problem, density, which are closely related from the point of view of a mathematical expert who could establish links among them - are clearly different from each other from the students' point of view, whom we understand have not yet created a complete image of the relationship between the different concepts that link the different models.

\section{Conclusions}

Firstly, the results obtained in this study allow us to assert that the students in the third cycle of Primary Education (ages 10-11) can face LNEP and to develop their own resolution methods. In fact, they introduce numerous elements in their team resolutions, which confirms the use of the mathematical models involved, such as grid distribution, reference point, and population density. In this sense, we concur with Peter-Koop (2004) on establishing the possibility of using Fermi Problems in Primary School classrooms. Along the same lines as Ärlebäck's (2011) statements, we have confirmed that LNEP - as are Fermi problems - may be useful to introduce modelling in classrooms. We can also state that these are accessible to Primary Education students without requiring any specific type of previous mathematical knowledge.

Secondly, we note that among the models detected in this study, the use of a grid distribution of people or objects stands out as the predominant way that Primary Education students deal with LNEP. In previous studies (Albarracín \& Gorgorió, 2014), we have not observed this marked prevalence of the grid distribution model, and we thus sense that grid distribution could be suggested as an initial model to introduce concepts such as population density. In fact, we can see how type A problems and problems B3 and B5 are good promoters of this model. Combining their use with problems such as B4 can help students to confront the need to create new models that exceed the possibilities offered by the use of the grid distribution. In this sense, we understand that developing sequences of Fermi problems in the framework of modelling 
eliciting activities (MEA) and modelling exploring activities (MXA) proposed by Ärlebäck \& Doerr (2015) - whose example we do not follow in the present work when designing classroom interventions - can be a good way to promote the conceptual jump required by Primary Education students to go from the grid distribution model to the reference point or density models that we have observed when working with students in Secondary Education. Hence, we highlight the importance of future study of the relationship that students establish between the concepts that link density, reference point models, and the reduction process to a smaller problem by proportionality.

In this work we have used problems that are contextualised in realities close to the students, with the intention of promoting the creation of mathematical models. From this viewpoint, Fermi problems strike as an adequate means to achieve this - especially when based on large number estimation. However, we understand that these problems may be used more ambitiously and can be geared towards answering questions relevant to Primary School students or that the teacher considers would help them grasp certain social aspects. This option has already been proposed by Sriraman and Knott (2009), and we consider that some of the problems featured in this study can be used in that direction. For instance, type A problems link up to counting the people attending protests or large events such as concerts or popular festivals. We understand that this is a way to clearly connect the use of mathematics to aspects of the students' everyday life and other STEM disciplines, and thus help the students to develop skills that give meaning to the results of mathematical problems in other disciplines.

\section{Acknowledgements}

Research supported by the projects EDU2017-82427-R (Ministerio de Economía, Industria y Competitividad, Spain) and 2017 SGR 497 (AGAUR, Generalitat de Catalunya).

\section{References}

Albarracín, L., \& Gorgorió, N. (2013). Problemas de estimación de grandes cantidades: modelización e influencia del contexto. Revista latinoamericana de investigación en matemática educativa, 16(3) 289315.

Albarracín, L., \& Gorgorió, N. (2014). Devising a plan to solve Fermi problems involving large numbers. Educational Studies in Mathematics, 86(1), 79-96.

Albarracín, L., \& Gorgorió, N. (2015). A brief guide to modelling in secondary school: estimating big numbers. Teaching Mathematics and Its Applications, 34(4) 223-228.

Albarracín, L., \& Gorgorió, N. (2018). Students estimating large quantities: from simple strategies to the population density model. EURASIA Journal of Mathematics, Science and Technology Education, 14(10), em1579.

Anderson, P. M., \& Sherman, C. A. (2010). Applying the Fermi estimation technique to business problems. The Journal of Applied Business and Economics, 10(5), 33-42.

Ärlebäck, J. B. (2009). On the use of realistic Fermi problems for introducing mathematical modelling in school. The Montana Mathematics Enthusiast, 6(3), 331-364.

Ärlebäck, J. B. (2011). Exploring the solving process of groups solving realistic Fermi problem from the perspective of the anthropological theory of didactics. In M. Pytlak, E. Swoboda \& T. Rowland (Eds.) Proceedings of the Seventh Congress of the European Society for Research in Mathematics Education (CERME7), (pp. 1010-1019). Rzeszów: University of Rzeszów, Poland.

Ärlebäck, J. B., \& Doerr, H. M. (2015b. Moving beyond a single modelling activity. In G. Stillman, W. Blum \& M. S. Biembengut (Eds.), Mathematical Modelling in Education Research and Practice, (pp. 293-303). Dordrecht: Springer.

Blum, W. (2002). ICMI Study 14: Applications and modelling in mathematics education-Discussion document. Educational Studies in Mathematics, 51(1), 149-171.

Blum, W., \& Borromeo Ferri, R. B. (2009). Mathematical modelling: Can it be taught and learnt? Journal of Mathematical Modelling and Application, 1(1), 45-58. 
Borromeo Ferri, R. (2006). Theoretical and empirical differentiations of phases in the modelling process. ZDM, $38(2), 86-95$.

Bright, G.W. (1976). Estimation as part of learning to measure. National Council of Teachers of Mathematics Yearbook, 38, (pp. 87-104). Reston, VA: NCTM.

Carlson, J. E. (1997). Fermi problems on gasoline consumption. The Physics Teacher, 35(5), 308-309.

Efthimiou, C. J., \& Llewellyn, R. A. (2007). Cinema, Fermi problems and general education. Physics Education, 42(3) 253.

Gallart, C., Ferrando, I., García-Raffi, L. M., Albarracín, L., \& Gorgorió, N. (2017). Design and implementation of a tool for analysing student products when they solve fermi problems. In G. A. Stillman, W. Blum \& G. Kaiser (Eds.), Mathematical Modelling and Applications. Crossing and Researching Boundaries in Mathematics Education, (pp. 265-275). Cham, Switzerland: Springer.

Hogan, T. P., \& Brezinski, K. L. (2003). Quantitative estimation: One, two, or three abilities? Mathematical Thinking and Learning, 5(4) 259-280.

Joram, E., Gabriele, A. J., Bertheau, M., Gelman, R., \& Subrahmanyam, K. (2005). Children's use of the reference point strategy for measurement estimation. Journal for Research in Mathematics Education, $36(1), 4-23$.

Jurdak, M. E. (2006). Contrasting perspectives and performance of high school students on problem solving in real world situated, and school contexts. Educational Studies in Mathematics, 63(3) 283-301.

Lesh, R., \& Harel, G. (2003). Problem solving, modeling, and local conceptual development. Mathematical Thinking and Learning, 5(2), 157-189.

Lester, F. K. (1994). Musings about mathematical problem-solving research: 1970-1994. Journal for Research in Mathematics Education, 25(6), 660-675.

Peter-Koop, A. (2004). Fermi problems in primary mathematics classrooms: Pupils' interactive modelling processes. In I. Putt, R. Faragher, \& M. McLean (Eds.), Mathematics education for the third millennium: Towards 2010. Proceedings of the 27th annual conference of the Mathematics Education Research Group of Australasia, (pp. 454-461). Sydney: MERGA.

Robinson, A. W. (2008). Don't just stand there-teach Fermi problems! Physics Education, 43(1), 83-87.

Schoenfeld, A. H. (2007). Problem solving in the United States, 1970-2008: Research and theory, practice and politics. ZDM, 39(5-6), 537-551.

Sriraman, B., \& Knott, L. (2009). The mathematics of estimation: Possibilities for interdisciplinary pedagogy and social consciousness. Interchange, 40(2) 205-223.

Tok, S.., Bahtiyar, A., \& Karalök, S. (2015). The effects of teaching mathematics creatively on academic achievement, attitudes towards mathematics, and mathematics anxiety. International Journal of Innovation in Science and Mathematics Education 23(4), 1-24.

Van de Walle, J. A., Karp, K. S., \& Bay-Williams, J. M. (2010). Elementary and middle school mathematics: Teaching developmentally. USA: Pearson.

Vorhölter, K., Kaiser, G. \& Borromeo Ferri, R. (2014). Modelling in mathematics classroom instruction: an innovative approach for transforming mathematics education. In Y. Li, E. A. Silver, \& S. Li (Eds.), Transforming Mathematics Instruction, (pp. 21-36). Cham, Switzerland: Springer.

White, H. B. (2004). Math Literacy. Biochemistry and Molecular Biology Education, 32(6), 410-411. 